JORGE F. HERNÁNDEZ

\title{
El poder de la biografía
}

\author{
"Hay un sabor que nuestro tiempo (hastiado, acaso, por las \\ torpes imitaciones de los profesionales del patriotismo) no \\ suele percibir sin algún recelo: el elemental sabor de lo \\ heroico". \\ Jorge Luis Borges \\ El pudor de la historia
}

\section{LOS PROFESIONALES DE NUESTRO PATRIOTISMO} llevan mucho tiempo bronceando nuestra historia con biografías epopéyicas y monumentales. En tiempos recientes han surgido, afortunadamente, estandartes y arengas que nos permiten desmitificar a Beneméritos y Siervos, de manera que a los Padres de la Patria se les conozca no sólo como estatuas altotas y a los Niños Héroes se les descubra de su envoltura en la bandera. Estos decobijamientos van de la mano de esa forma de historear, honrada por los trabajos de D. Luis González, que llamamos (gracias a él) microhistoria.

Esta labor matriótica se aboca a los terruños y vuelve universales los espacios microscópicos; claramente provinciana, se trata de una historia cuyo encanto se hace eco de chismes y cantos, correspondencias y periódicos, cuentos y poemas, registros y decretos. Pero la historia matria permite entrever que no se trata de una labor parroquial o municipal. Es un afán de desensalzar y conocer más allá de estructuras, marcos teóricos, coyunturas dinámicas de procesos naturales, etc.

Así, podemos ubicar a La biografía del poder como una investigación histórica que, más que proponerse realizar una cronología milimétrica de la Revolución Mexicana, se concentra en ocho espacios biográficos cuya duración temporal corta permite entender una duración larga que llega hasta nuestros días.

Más allá de una descripción simplista, de por sí ya recontra- 
conocida por todos, la biografía realizada por Enrique Krauze presenta facetas, colores, caras e incluso llantos que los profesionales de nuestro patriotismo han recubierto en las estampas de papelería. Aun habiendo aprobado los cursos primarios de historia patria no podemos realmente ejercer nuestra historia si no nos atrevemos a comprenderla con toda su crueldad y con toda su bondad, con su color y su sombra. Así, al recorrer los primeros cuatro episodios, Krauze va mostrando una cadena de dualidades dinámicas: democracia y tiranía, paz bélica y traiciones solidarias.

Resulta interesante observar que esta biografía del poder goza de un amplio espacio de difusión: precios populares de la edición y acompañamiento en todos los canales de T.V. y a distintos hotarios. Pero más allá del impacto que provocan, tanto la extraordinaria investigación iconográfica como la excelente producción fílmica, el poder de esta biografía reside en la posibilidad de conocer los ires y venires, los dimes y diretes, los abrazos y los balazos de quienes vivieron y forjaron épocas de nuestro pasado, pero sin retocarlos con pinturas patrióticas ni cubrirlos con velos que justifiquen presentes.

\section{Dos místicos}

Acostumbrados a considerar a Porfirio Díaz solamente como el tirano-senil, nos debe sorprender el interés que despierta su condición de Místico de la autoridad. Imagino que es primera vez, por lo menos desde que "se desató al tigre", que un proyecto histórico de gran alcance no hable del Antiguo Régimen solamente en términos de dictadura y que, además, no sólo vea a Don Porfirio como Don Perpetuo.

Krauze le sigue los pasos a este místico desde que Porfirio era joven militar oaxaqueño, ligado al otro oaxaqueño abogado y antes pastorcito, hasta que se convierte en el Don afrancesado de largos bigotes blancos. Se ven los pasos de Díaz en sus relaciones amorosas: bailes con Juana Cata y conciertos de fin de siglo con Doña Carmelita, ya sentado.

El primer tomo de la Biografía está dedicado al místico que, mientras luchó por la silla, fue aclamado Héroe, pero que, cuando artríticamente se quedó ensillado, fue derrocado como cualquier tirano. No debe malinterpretarse el ánimo histórico: estudiar la figura de Porfirio Díaz historiando no sólo las críticas, y los odios que obviamente se ganó, no quiere decir que se le está justificando; simplemente, se procura conocerlo. 
Se trata entonces, de historear en esta Biografía del poder partiendo más allá del " Viva Madero! ¡Muera el Dictador!”, pero sin llorar al pie del Ipiranga, como Susanito Peñafiel; de conocer la biografía de quien combatió a los "monsieures" en Puebla, se le rebeló al Benemérito Juárez, promulgó ideas de progreso y ciencia, oprimió y ejerció un poder total de terrorífica "paz" y sangrienta "estabilidad". Pero se trata también de conocer al que lloraba en público cuando se le trababa el discurso, al señorón reluciente que seguía escupiendo en la alfombra, al que se inyectó sangre azul sin quitarse el "máis" y el "te truje". Posiblemente la mejor forma de conocer el por qué del "Viva Madero" sea revisar los años eternos que precedieran ese grito y, para eso, no podemos quedarnos en que a Don Porfirio se le tumbó, sino conocerlo desde su joven circunstancia en Oaxaca hasta sus cortos pasitos en París.

Otro místico ocupa el siguiente espacio y su apostolado culmina, como buen predicador, en el martirio. La Decena Trágica y el asesinato del poder ejecutivo son los acontecimientos más conocidos del Místico de la libertad. Pero se trata de su calvario, del mero final. Aquí, una vez más, Krauze nos presenta caminos ignotos: los de Francisco 1. Madero, de manera que descubrimos a un personaje místico sin adjetivos.

La biografía de Madero reúne ingredientes de espiritismo y homeopatía que nos dejan entender mejor sus prédicas y luchas por Democracia, más allá del ya golpeado "Sufragio Efectivo, No Reelección". Para quien sólo conoce a Madero como el pequeño mártir de la novelada revolufia, su opinión se asemeja al grito de los que, sin poder verlo, coreaban: "Viva Madero".

Ya no se debe a su estatura, ni parece que sea por la velocidad de las películas, pero la figura de Madero, tal vez convenientemente para algunos, se nos presenta difusa y poco conocida. Aquí al poder de la biografía nos invita a discursos y proyectos realmente democráticos. Conocemos épocas, lejanas, de sufragios efectivos y algarabías populares sin acarreamientos. Lamentablemente se trata de una época de planes y prácticas que duró muy poco tiempo; de un ánimo democrático que sugirió traición y que fue asesinado. Pero lejos de hacer una investigación que, nuevamente, se convierta en la apologética de Madero y Pino Suárez, Krauze rastrea los ingredientes internos que los llevaron a su fin.

Es decir, más allá de la traición del usurpador Huerta y de los ánimos restaruadores de Félix Díaz y Bernardo Reyes, había una ingenuidad mística en Madero. Una confianza en la Providencia 
y en el concierto impalpable de los espíritus universales que lo llevaron a creerse mentiras y a acompañarse de mentirosos. Como bien señala Krauze, la repuesta a estas conjeturas "pertenece al dominio de la mística, no al de la política", pero al dominio de la historia sí le conviene entender, o por lo menos, conocer estas sus otras caras. Si el lema de la homeopatía proclama Similia Similibus Curantor, tal vez a la mística maderista le faltó una dosis, no fuerte pero resistente, de la mística porfirista que intentó sustituir: Autoridad.

\section{El Guerrero y El Guerrillero}

Otra dualidad, con muchas diferencias intrínsecas, es pareja en esta Biografía del poder; Francisco Villa y Emiliano Zapata son Norte y Sur, Risa y Seriedad, Guerra y Guerrilla en nuestra historia.

En el espacio que ocupa la mirada de Zapata se percibe $E l$ amor a la tierra y, por tanto, se recrea la investigación microhistórica. El Caudillo del Sur lleva a cabo una revolución matriótica, propia. El estandarte de Guadalupe y los renglones del Plan de Ayala son postulados locales con circunstancias particulares y con siglos de espera. Zapata lucha por reivindicar ánimos ancestrales y cada arranque de sus tropas se respalda en legajos, copias, reclamos y quejas que se ubican con nombres en náhuatl y mapas rústicos. Zapata es pues, el guerrillero amante de la tierra, que no pretende realizar planes macroscópicos ni asiste a la Convención de Aguascalientes.

Villa, al otro lado, es el guerrillero vuelto guerrero de quepí y uniforme. Pero es en sí el norteño que se ubica Entre el ángel y el fierro, entre las ganas de matar y la estrategia balística, matemática, de planear y hasta perdonar. Pancho Villa, entre Doroteo Arango y General Villa, es el que "quiebra" a los "curritos" y ríe con todos los niños. El sí asiste a Convenciones y, mientras muestra cañones y treintas-treintas, llora ante emociones que le llegan. Frente al "terror místico" que siente Zapata ante la Silla Presidencial, Villa se sienta en ella a carcajadas y, a diferencia de "La tierra" de Emiliano, se contenta con hablar de "las tierritas".

Nuevamente el poder de la biografía permite que Krauze nos muestre los ánimos y los respaldos de personajes mitificados, exagerados, descónocidos. La historia posee la gracia de poder acercanos a espacios casi irreales, pero imaginables. La dualidad del guerrero y guerrillero muestra los diferentes bigotes de cada uno. La biografía incursiona, con mayor frecuencia que en los 
otros espacios, en los humos del terror. Con los pasos y galopes de Zapata y Villa la historia recorre campos sangrientos y llanos repletos de cuerpos, percibe olores de locomotora y pólvora y escucha ruideros de miles de "revolucionados", corridos y polkas populares.

Tanto el guerrero como el guerrillero encuentran muerte trágica. Ambos, buscando su pistola, no logran enfrentar la lluvia de balazos. Krauze deja en el aire de qué color era el cráneo de Villa, si de Angel o de Fierro. Con Zapata, la biografía recoge los ánimos de que el asesinado en Chinameca no era Emiliano, sino otro. En ambos casos, la biografía está rescatando el carácter místico y legendario que cobraron al paso del tiempo los jinetes.

El poder de la biografía debe permitirnos romper con historias oficiales y observar a los próceres como seres humanos en todos sus renglones posibles. Posiblemente por tratarse de un tiraje editorial popular acompañado, además, por una serie de televisión, La biografía del poder no deja de ser un panorama amplio. Su mérito está en poner a nuestro alcance el conocimiento de las biogrfías de quienes se destacaron en nuestra historia, permitiéndonos intentar comprenderlos antes de seguirlos juzgando. Lejos de quedarnos en los lugares comunes de discursos y panfletos, la biografía (como cara de la historia) nos brinda el poder de descubrir el pasado, liberándonos de él y probar, sin artificios, "el elemental sabor de los heróico". 